\title{
Bystander behavior in bullying situations: basic moral sensitivity, moral disengagement and defender self-efficacy
}

Robert Thornberg and Tomas Jungert

\section{Linköping University Post Print}

\section{Tweet}

N.B.: When citing this work, cite the original article.

Original Publication:

Robert Thornberg and Tomas Jungert, Bystander behavior in bullying situations: basic moral sensitivity, moral disengagement and defender self-efficacy, 2013, Journal of Adolescence, (36), 3, 475-483.

http://dx.doi.org/10.1016/j.adolescence.2013.02.003

Copyright: Elsevier

http://www.elsevier.com/

Postprint available at: Linköping University Electronic Press

http://urn.kb.se/resolve?urn=urn:nbn:se:liu:diva-91057 


\title{
Bystander behavior in bullying situations: Basic moral sensitivity, moral disengagement and defender self-efficacy
}

\author{
Robert Thornberg \& Tomas Jungert \\ Linköping University, Linköping, Sweden
}

\begin{abstract}
The aim of the present study was to investigate how basic moral sensitivity in bullying, moral disengagement in bullying and defender self-efficacy were related to different bystander behaviors in bullying. Therefore, we examined pathways that linked students' basic moral sensitivity, moral disengagement, and defender self-efficacy to different bystander behaviors in bullying situations. Three hundred and forty-seven teenagers completed a bullying survey. Findings indicated that compared with boys, girls expressed higher basic moral sensitivity in bullying, lower defender self-efficacy and moral disengagement in bullying. Results from the SEM showed that basic moral sensitivity in bullying was negatively related to pro-bully behavior and positively related to outsider and defender behavior, mediated by moral disengagement in bullying, which in turn was positively related to pro-bully behavior and negatively related to outsider and defender behavior. What differed in the relations between outsider and defender behaviors was the degree of defender self-efficacy.
\end{abstract}

Keywords: Bullying, Bystander, Defender, Basic moral sensitivity, Moral disengagement, Defender self-efficacy

Bullying, defined as repeated aggression directed at students who are disadvantaged or less powerful in their interactions with the bully or bullies (Jimerson, Swearer, \& Espelage, 2010; Olweus, 1993), is a pervasive problem in schools throughout the world (e.g., Eslea et al., 2003; Harel-Fisch et al., 2011). Bullying is a social process, and in most school bullying situations, other students not directly involved as bullies or victims are present as bystanders (e.g., Craig, Pepler, \& Atlas, 2000). According to the participant role approach (Salmivalli, 1999; Salmivalli, Lagerspetz, Björkqvist, Östermalm, \& Kaukiainen, 1996), students who observe bullying can assume a range of different roles: assistants, who join the bullies and begin to bully the victim; reinforcers, who support the bullies by cheering and laughing; outsiders, who remain passive or uninvolved with the bullying; and defenders, who try to help or support the victim. Nevertheless, findings from observational studies indicate that bystanders seldom act in ways that support the victims (e.g., Craig et al., 2000; O'Connell, Pepler, \& Craig, 1999). In a recent study, former victims were asked what it was that made the bullying stop in their cases. Very few of them reported that bullying had stopped because of support from peers (Frisén, Hasselblad, \& Holmqvist, 2012). At the same time, research has shown that bullying is more frequent in school settings where bystanders display more behaviors that reinforce bullying and less frequent when bystanders are more prone to defend the victims (Kärnä, Voeten, Poskiparta, \& Salmivalli, 2011; Salmivalli, Voeten, \& Poskiparta, 2011). Research on bystander behavior in bullying has revealed that defender behavior is more or less associated with empathy, anti-bullying attitudes, pro-victim attitudes, a sense of social justice, low moral disengagement, a high sense of responsibility, high social status, friendship with the victim, perceived peer pressure to help, and social and defender self-efficacy (Bellmore, Ma, You, \& Hughes, 2012; Cappadocia, Pepler, Cummings, \& Craig, 2012; Obermann, 2011 a; Oh \& Hazler, 2009; Pozzoli, Ang, \& Gini, 2012; Pozzoli \& Gini, 2010; Pozzoli, Gini, $\&$ Vieno, 2012b; Thornberg et al., 2012). The scope of the present study was to investigate how morality (basic moral sensitivity in bullying, and moral disengagement in bullying) and defender self-efficacy were related to different bystander behavior among adolescents in bullying situations. 


\section{Basic moral sensitivity}

According to social-cognitive domain theory, morality refers to "conceptions of human welfare, justice, and rights, which are functions of the inherent features of interpersonal relations" (Nucci, 2001, p. 7), and is cognitively structured around considerations of the intrinsic effects that an individual's actions have on the well-being of other people. In contrast, social conventions are shared norms and expectations based on authority, traditions or customs regarding appropriate behavior in different social contexts (Nucci, 2001; Turiel, 1983). Previous research has shown that children and adolescents judge moral transgression as more wrong and severe than conventional transgressions. They most often justify judgments of moral issues in terms of the harm or unfairness that actions cause, whereas they most often justify judgments of social conventions in terms of social norms, social expectations, customs and authority (e.g., Davidson, Turiel, \& Black, 1983; Nucci, 1981; Nucci, Camino, \& Sapiro, 1996; Tisak, Crane-Ross, Tisak, \& Maynard, 2000; Thornberg, 2010; Turiel, 2008).

According to the four-component model of moral functioning (Bebeau, Rest, \& Narvaez, 1999; Jordan, 2007; Narvaez \& Rest, 1995; Narvaez \& Vaydich, 2008; Rest, 1985), four psychological processes occur in normal moral functioning: moral sensitivity, moral judgment, moral motivation, and moral character. Of interest in this study is the first component, moral sensitivity, defined by Jordan (2007) as "the ability to recognize moral issues in complex situations" (p. 325). It includes dimensions such as interpreting others' reactions and feelings, having empathy and role-taking ability, understanding how actions can affect the welfare of the self and others, and making inferences from others' behavior and responding appropriately to their reactions. Based on the core definition of morality in social-cognitive domain theory, we would like to propose the concept of basic moral sensitivity to refer to an individual's readiness in morally simple situations to recognize moral transgressions and their harming consequences toward others, a sensitivity related to aroused moral emotions such as empathy, sympathy, or guilt. In normal moral functioning, such "hot" affective content is associated with the construction of moral-action schemas and has been integrated within the overall conceptual framework guiding the child or adolescent's morality (Hoffman, 2000; Nucci, 2001).

In contrast to a morally complex situation in which moral ambiguity is created because of the presence of moral dilemmas (i.e., conflicts between different moral norms), a morally simple situation, as we define it, is a situation in which a moral transgression is unambiguously wrong because of its inherent harm toward a person in a weaker or socially disadvantaged position in relation to the perpetrator or perpetrators. Bullying, harassment and discrimination are all prototypes of a morally simple situation - it is easy to recognize the moral wrongness in the situation and become emotionally aroused without conscious, cognitive efforts but as a result of automatic information processing. Basic moral sensitivity can therefore be seen as an example of preconscious automaticity, that is, "involuntary activation of social constructs (e.g., schemas, scripts, plans, stereotypes, prototypes) outside of conscious awareness, as a result of a triggering event ... and [if chronically or easily accessible, it] exerts a pervasive interpretative influence over social information-processing and underwrites social judgments of all kinds" (Narvaez \& Lapsley, 2005, p.144). Preconscious automatically is responsible for individuals' strong feelings of certainty or conviction regarding their social judgments (Narvaez \& Lapsley, 2005). The moral domain structures, which are formed through repeated social interactions that share the core features of "actions that cause others harm," are latent mental structures that - if activated - inform and influence children's and adolescents' social information processing in a given situation (Arsenio \& Lemerise, 2004). Whereas the majority of children and adolescents perceive bullying as something wrong by referring to its harming consequences, there are those who do not express that perception 
(Perren, Gutzwiller, Malti, \& Hymel, 2012; Thornberg, 2010), which indicates individual variation in basic moral sensitivity. In line with that, Caravita, Miragoli, and Di Blasio (2009) found that bullies and assistants tend to attribute social-conventional characteristics to moral issues more than their peers do.

\section{Moral disengagement}

As outlined in the social-cognitive theory of agency (Bandura, 1999, 2002), moral disengagement is a set of socio-cognitive processes through which people can disengage from humane acts and instead commit inhumane, harassing, harming, or horrible actions against other people. Specifically, Bandura proposed eight moral disengagement mechanisms clustered into four broad processes. The first, cognitive restructuring, refers to the re-construal of the conduct itself so that it is not viewed as immoral as a result of (a) using worthy ends or moral purposes to condone pernicious means (moral justification), (b) labeling the negative or harming act in a way that makes the act sound less negative or more respectable (euphemistic labeling), or (c) making a malicious act seem "less bad" by comparing it to a worse or more negative act (advantageous comparison). Minimizing one's agentive role is the second main process and refers to detaching or obscuring oneself from personal responsibility for the act of harming (displacement or diffusion of responsibility). The third set of moral disengagement mechanisms operates by disregarding or distorting the consequences (minimizing, ignoring, or misconstruing the negative or harmful effects of actions), thus making it easier for the individual to avoid facing the harm the action causes. Finally, through victim attribution, the bully avoids moral distress by stripping the victim of human qualities and egalitarian values (dehumanization) or thinking that the victim deserves the harm or suffering inflicted on him or her (blaming the victim).

Moral disengagement has been positively related to aggression (Bandura, Barbaranelli, Caprara, \& Pastorelli, 1996; Bandura, Caprara, Barbaranelli, \& Pastorelli, 2001; Paciello, Fida, Tramontano, Lupinetti, \& Caprara, 2008; Pelton, Gound, Forehand, \& Brody, 2004; Pornari \& Wood, 2010), including bullying behavior (Gini, Pozzoli, \& Hauser, 2011; Hymel, Rocke-Henderson, \& Bonanno, 2005; Menesini et al., 2003; Obermann, 2011b; Perren et al., 2012), and negatively related to prosocial behavior (Bandura et al., 1996, 2001). Gini (2006) found that students who were peer-nominated as bullies, assistants or reinforcers, demonstrated higher moral disengagement than defenders. The positive link between moral disengagement and pro-bully behavior (i.e., acting as assistants or reinforcers when witnessing bullying) was also found by Pozzoli, Gini, and Vieno (2012a). According to a study by Almedia, Correia, and Marinho (2010), students with high moral disengagement had more negative attitudes regarding the role as a defender. However, moral disengagement appears not to differentiate between outsiders and defenders, because both bystander behaviors are usually associated with comparably low levels of moral disengagement (Gini, 2006; Menesini et al., 2003). Obermann (2011a) found, however, that unconcerned passive bystanders showed a higher level of moral disengagement compared with guilty passive bystanders (i.e., those who remain passive but think they ought to help the victim) and defenders. We assumed that it would be harder for adolescents to morally disengage if their basic moral sensitivity is high. Hence, we hypothesized that basic moral sensitivity should be negatively associated with moral disengagement in bullying.

\section{Defender self-efficacy}

Helping a peer in distress, such as in a bullying situation, is a risky project (Dovidio, Piliavin, Schroeder, \& Penner, 2006). Without an individual's strong belief in his or her ability to successfully intervene, carrying out such behavior would be inhibited. Self-efficacy is the belief in one's capabilities to successfully organize and execute a particular action required to pro- 
duce the desired results (Bandura, 1986, 1997). Recent bullying research has found that, consistent with the self-efficacy framework, defender self-efficacy is positively associated with defender behavior (Barchia \& Bussey, 2011; Pöyhönen, Juvonen, \& Salmivalli, 2012). In addition, Gini, Albiero, Benelli, and Alto (2008) reported that social self-efficacy is positively associated with defender behavior and negatively associated with outsider behavior. In a study by Cappadocia et al. (2012), social self-efficacy predicted bystander intervention among girls but not among boys. However, the area of research on the relationship between defender self-efficacy and the full range of bystander roles in bullying is still unexplored. With reference to the work of Gini et al. (2008), we hypothesized that defender self-efficacy would be positively associated with defender behavior and negatively associated with outsider behavior.

\section{Aims}

The aim of the present study was to investigate how basic moral sensitivity in bullying, moral disengagement in bullying and defender self-efficacy were related to different bystander behaviors in bullying. Therefore, we examined pathways that linked students' basic moral sensitivity in bullying, moral disengagement in bullying, and defender self-efficacy to different bystander behaviors (pro-bully, outsider, or defender behavior) in bullying situations.

The first hypothesis in our model refers to the relations between basic moral sensitivity, moral disengagement and pro-bully behavior (i.e., assistant and reinforcing behaviors), outsider behaviors, and defender behavior. We hypothesized that basic moral sensitivity negatively contributes to pro-bully behavior and positively to outsider and defender behavior in bullying situations. This relation was hypothesized to be negatively mediated by moral disengagement in bullying. Hence, basic moral sensitivity was expected to be directly and negatively related to moral disengagement in bullying. Moral disengagement in bullying was hypothesized to be directly and negatively related to pro-bully behavior and positively related to outsider and defender behavior.

The second hypothesis in our model refers to the relation between defender self-efficacy and the three types of bystander behaviors. We expected defender self-efficacy to be directly and negatively related to outsider behavior and directly and positively related to defender behavior. Thus, whereas high level of basic moral sensitivity and low level of moral disengagement were assumed to increase the likelihood of both outsider and defender behavior, the level of defender self-efficacy was hypothesized to predict if adolescents were prone to act as defenders or outsiders.

\section{Method}

\section{Participants}

Three hundred and forty-seven teenagers (141 boys and 206 girls), attending three upper secondary schools in a medium-sized Swedish town, participated in the study on a voluntary basis. The age range was $15-20$ years $(m=17.4$ years; $s d=.98)$. Ninety-nine per cent of the participants were in the 16-19-year-old-range. Socio-economic background data were not gathered on an individual level. Nevertheless, because the sample represented different types of educational programs and because students' choice of attending an educational program in upper secondary schools in Sweden is influenced by their socio-economic background, this stratified sampling strategy ensured that the sample in this study represented students from lower-class and middle-class families. Vocational programs are linked to lower socioeconomic status, and academic programs are associated with higher socio-economic status. 


\title{
Procedure and measures
}

As a part of a university-school collaboration to investigate upper secondary school students' retrospective bullying experiences from elementary school and secondary school and their attitudes and beliefs about bullying, we developed a 99-item student survey in consultation with students and teachers from several schools. The students who participated in the present study were given this survey and filled it out sitting in their ordinary classroom setting. A student teacher, at the end of her teacher training, was present in every classroom during the data gathering, and the definition of bullying, according to Olweus's (1993) definition, given on the very front page of the questionnaire to the participants, was read aloud.

\begin{abstract}
Bullying means that a student, or a group of students, repeatedly says or does nasty and unpleasant things to another student. It's also bullying when others repeatedly exclude a student. But it's not bullying when two students - of about the same strength - quarrel or fight. Jokes between friends are not bullying if everyone involved thinks it's okay. But it's bullying if a student, or a group of students, repeatedly makes fun of or teases another student in a way he or she doesn't like.
\end{abstract}

The items of interest in the present study tapped students' self-reported basic moral sensitivity in bullying, moral disengagement in bullying, defender self-efficacy, and bystander behaviors. In the survey, three items measured to what degree students recognized the harming effects of bullying and sympathize with victims ("A person who is subjected to bullying suffers terribly"; "Bullying harms the victim for a very long time"; "I really feel sorry for the kids getting bullied"; Cronbach's $\alpha=.68$ ), which were rated on a 7-point scale (from $1=$ "not true at all" to 7 = "very true"). In a post hoc manner, we reviewed these items in the survey and identified them as reflecting the construct of basic moral sensitivity (in bullying). Six items measured to what degree students reasoned in ways that justify bullying, blame the victim, and undermine the seriousness of bullying ("Bullying is okay in certain cases"; "It's okay to bully someone who you don't like"; "One good thing about bullying is that the victim learns how to behave and how not to behave in order to be accepted"; "Bullying really isn't so bad ... something you have to put up with"; "A person who is bullied only has him- or herself to blame"; "Some people deserve to be bullied"; Cronbach's $\alpha=.83$ ) rated on a 7-point scale (from $1=$ "not true at all" to $7=$ "very true"). In a post hoc manner, we reviewed these items in the survey and identified them as reflecting the construct of moral disengagement (in bullying) outlined by Bandura (1999, 2002). The six items tapping students' moral disengagement obviously did not cover all eight mechanisms of moral disengagement. Factor analyses conducted by other researchers on previous moral disengagement scales, however (Bandura et al., 1996, 2001; Hymel et al., 2005), have always revealed a one-factor structure with all items loading on a single factor and a very high alpha reliability coefficient for the whole scale. These previous outcomes indicate high inter-correlations between all items and, hence, high inter-relations between the sub-constructs, in each previous scale. Hence, tapping only some of the aspects of moral disengagement, as in the current study, still should remain a good estimate of the whole construct of moral disengagement. Furthermore, two items tapped students' defender self-efficacy ("If I saw bullying, I'm sure I would be able to stop it"; "I have a high confidence in my ability to intervene in bullying situations and help the victim"; $r=.62)$.

Student Bystander Behavior Scale (SBBS): Eight items in the survey tapped possible prior experiences of bystander roles. The four bystander roles from the participant role approach (Salmivalli, 1999; Salmivalli et al.,1996) were used. The students were asked, "If you saw one or some kids bullying another kid in school, how did you use to react when you saw the bullying going on?" A set of items, rated on a 5-point scale (1= "never," $2=$ "seldom," $3=$ "sometimes," 4= "usually," 5= "always") followed the question. Two items tapped the assis- 
tant role, two items tapped the reinforcer role, two items tapped the outsider role, and two items tapped the defender role.

Exploratory factor analysis was carried out using the Maximum Likelihood (ML) algorithm and the Direct Oblimin rotation as a first step of a validation of the SBBS. Factor loading and scree tests were used to select a parsimonious model. Both a four-factor and a threefactor model were tested. The four-factor model explained $79 \%$ of variance, 89 iterations were required to extract the four factors, and the scree plot indicated that the optimal model would be either a two-factor or a three-factor model. There were several further cross-loadings with one outsider behavior item loading on the defender behavior factor, and more importantly, the two reinforcer behavior items and the two assistant behavior items all crossloaded on the same two factors. The three-factor model explained $73 \%$ of variance and required four iterations. The three factors were correlated $(r=-.14,-.31$, and -.19). One defender behavior item double-loaded on the outsider behavior factor (-.46), but no item had a loading below .70 on its own factor. We concluded that the first factor with four items assessed probully behavior (Cronbach's $\alpha=.82$ ), the second factor with two items assessed outsider behavior $(r=.49)$, and the third factor with two factors assessed defender behavior $(r=.46)$. We decided to pursue this model in order to differentiate between the three forms of bystander behaviors, and tested it using CFA. The three statistics (CFI $=.94$; S-BSS $/ \mathrm{df}=59.18 / 17=3.47$; RMSEA $=.09 ; 90 \%$ CI $[0.06,0.10])$ indicate an acceptable fit. Table 1 below shows the factor loadings (standardized solution) and how indicators F1 through F3, synonymous with these three factors, were computed.

Table 1

Validation of the Bystander behaviour scale.

\begin{tabular}{|c|c|c|c|}
\hline Item & $\begin{array}{l}\text { F1: Defender } \\
\text { behaviour }\end{array}$ & $\begin{array}{l}\text { F2: Outsider } \\
\text { behaviour }\end{array}$ & $\begin{array}{l}\text { F3: Pro-bully } \\
\text { behaviour }\end{array}$ \\
\hline I tried to get the bully/bullies to stop & .87 & & \\
\hline I told a teacher & .53 & & \\
\hline I didn't do anything but I was quiet and passive instead & & .90 & \\
\hline I stayed away & & .55 & \\
\hline I joined in and began to bully the student too & & & .80 \\
\hline I took the bullies' side and joined in the bullying & & & .77 \\
\hline I watched because it was fun and entertaining & & & .73 \\
\hline I laughed and cheered the bullies on & & & .70 \\
\hline
\end{tabular}

\section{Results}

\section{Descriptive results}

The means and standard deviations and the matrix of correlations between all variables are presented in Table 2. Correlations among the different bystander behaviors ranged from -.17 to -.38 . Basic moral sensitivity in bullying situations was negatively associated with pro-bully behavior and positively associated with defender behavior and outsider behavior. In contrast, moral disengagement in bullying situations was positively associated with pro-bully behavior and negatively associated with defender behavior and outsider behavior. In addition, basic moral sensitivity and moral disengagement in bullying situations were negatively intercorrelated. Moreover, defender self-efficacy was positively associated with defender behavior and negatively correlated with outsider behavior. Because gender was associated with all other variables, mean differences based on gender were further explored.

Six one-way ANOVAs showed significant differences in all measures. Compared with boys $(m=5.16, s d=1.53)$, girls expressed significantly higher basic moral sensitivity in bullying $\left(m=6.20, s d=.95, F_{1,346}=60.90, p<001\right.$, partial $\left.\eta^{2}=.15\right)$. In contrast, boys 
displayed significantly higher moral disengagement in bullying $\left(m=2.19, s d=1.24, F_{1,346}=\right.$ 63.04, $p<.001$, partial $\left.\eta^{2}=.15\right)$ as compared with girls $(m=1.40, s d=.59)$. Defender selfefficacy was found to be significantly higher among boys $(m=4.22, s d=1.59)$ than girls $(m=$ $3.78, s d=1.45, F_{1,346}=7.21, p<.01$, partial $\left.\eta^{2}=.02\right)$. As bystanders in bullying, girls were significantly more prone to act as outsiders $(m=3.38, s d=.84)$ than boys $(m=2.96, s d=.96$, $F_{1,346}=18.65, p<.001$, partial $\left.\eta^{2}=.05\right)$ as well as to act as defenders $(m=2.63, s d=.91)$ than boys $\left(m=2.31, s d=.98, F_{1,346}=9.31, p<.01\right.$, partial $\left.\eta^{2}=.03\right)$. In contrast, boys were significantly more prone to act as pro-bullies $(m=1.63, s d=.65)$ when encountering bullying situations as bystanders as compared with girls $\left(m=1.26, s d=.38,, F_{1,346}=44.18, p<.001\right.$, partial $\left.\eta^{2}=.11\right)$.

Table 2

Means, standard deviations and inter-correlations between all variables.

\begin{tabular}{|c|c|c|c|c|c|c|c|c|}
\hline & $\mathrm{M}(\mathrm{SD})$ & 1 & 2 & 3 & 4 & 5 & 6 & 7 \\
\hline 1. Gender & & 1 & & & & & & \\
\hline $\begin{array}{l}\text { 2. Basic } \\
\text { moral }\end{array}$ & $5.77(1.32)$ & $.39 * * *$ & 1 & & & & & \\
\hline Sensitivity & & & & & & & & \\
\hline $\begin{array}{l}\text { 3. Moral } \\
\text { disengament }\end{array}$ & $1.72(0.99)$ & $-.39 * * *$ & $-.53 * * *$ & 1 & & & & \\
\hline $\begin{array}{l}\text { 4. Defender } \\
\text { self-efficacy }\end{array}$ & $3.96(1.52)$ & $-.14 * *$ & .06 & .03 & 1 & & & \\
\hline $\begin{array}{l}\text { 5. Pro-bully } \\
\text { behavior }\end{array}$ & $1.41(0.54)$ & $-.34 * * *$ & $-.37 * * *$ & $.56^{* * *}$ & -.10 & 1 & & \\
\hline $\begin{array}{l}\text { 6. Outsider } \\
\text { behavior }\end{array}$ & $3.21(0.91)$ & $.23 * * *$ & $.22 * * *$ & $-.26 * * *$ & $-.44 * * *$ & $-.17 * *$ & 1 & \\
\hline $\begin{array}{l}\text { 7. Defender } \\
\text { behavior }\end{array}$ & $2.50(0.95)$ & $.16^{* *}$ & $.31 * * *$ & $-.29 * * *$ & $.47 * * *$ & $-.38 * * *$ & $-.28 * * *$ & 1 \\
\hline
\end{tabular}

Note. Gender (boys $=0$, girls $=1$ ); $* *=p<.01 ; * * *=p<.001$

\section{The SEM analysis}

The structural model was tested using the EQS 6.1 (Bentler, 1995). The scores for the three bystander behaviors (pro-bully, outsider, and defender) were included in the model as dependents. The score for basic moral sensitivity was introduced as an independent that was mediated by the score for moral disengagement. The score of defender self-efficacy was also introduced as an independent.

Results of the SEM are shown in Figure 1, which includes all the standardized coefficients that are significant at and below the .05 level. The model-fit statistics for the model (N $=347$; CFI $=.92 ; \mathrm{S}-\mathrm{BSS}=258.44 \mathrm{df}=144 ; \mathrm{RMSEA}=.048,90 \% \mathrm{CI}[0.04,0.06])$ indicate an acceptable fit. The Wald test suggested no further modifications of the model, which allowed us to conclude that the model fits the sample. $\mathrm{R}^{2}$ values indicate that this model explains $51 \%$ of the variance for pro-bully behavior, $51 \%$ of the variance for outsider behavior, and $70 \%$ of the variance for defender behavior. Figure 1 shows all path coefficients.

The overall model showed a negative relation between basic moral sensitivity in bullying and moral disengagement in bullying. Basic moral sensitivity in bullying was indirectly and negatively related to pro-bully behavior, negatively mediated by moral disengagement in bullying, which in turn was directly and positively related to pro-bully behavior. Furthermore, basic moral sensitivity in bullying was indirectly and positively related to outsider and defender behavior, negatively mediated by moral disengagement in bullying, which in turn was 
directly and negatively related to both these behaviors. What differed in the relations between outsider and defender behaviors was defender self-efficacy. A strong negative relationship between defender self-efficacy and outsider behavior and a strong positive relationship between defender self-efficacy and defender behavior appear to explain, at least in part, why students who display high basic moral sensitivity and low moral disengagement in bullying decide either to intervene and help a victim or to remain passive.

Because we found significant gender differences in all measures, we also tested the structural model for both boys and girls. To carry out this step, the sample was divided into two samples: females and males. When we examined the parameters, the Wald test indicated that the parameter between moral disengagement and defender behavior in the first model for the female sample should be dropped in order to have a model with better fit to the data. Thus, this parameter was removed from further analyses. The model-fit statistics for the second model for the female sample $(\mathrm{N}=206$; $\mathrm{CFI}=.89$; $\mathrm{S}-\mathrm{BSS}=211.61 \mathrm{df}=145$; $\mathrm{RMSEA}=.047,90 \%$ CI $[0.03,0.06])$ and the male calibration sample $(\mathrm{N}=141$; $\mathrm{CFI}=.91$; S-BSS $=212.59 \mathrm{df}=144$; RMSEA $=.058,90 \%$ CI $[0.04,0.07])$ indicated models with an acceptable fit. $\mathrm{R}^{2}$ values for the female sample model indicate that this model explains $14 \%$ of the variance for pro-bully behavior, $54 \%$ of the variance for outsider behavior, and $69 \%$ of the variance for defender behavior. $\mathrm{R}^{2}$ values for the male sample model indicate that this model explains $45 \%$ of the variance for pro-bully behavior, $46 \%$ of the variance for outsider behavior, and $69 \%$ of the variance for defender behavior. Figure 2 shows all path coefficients.

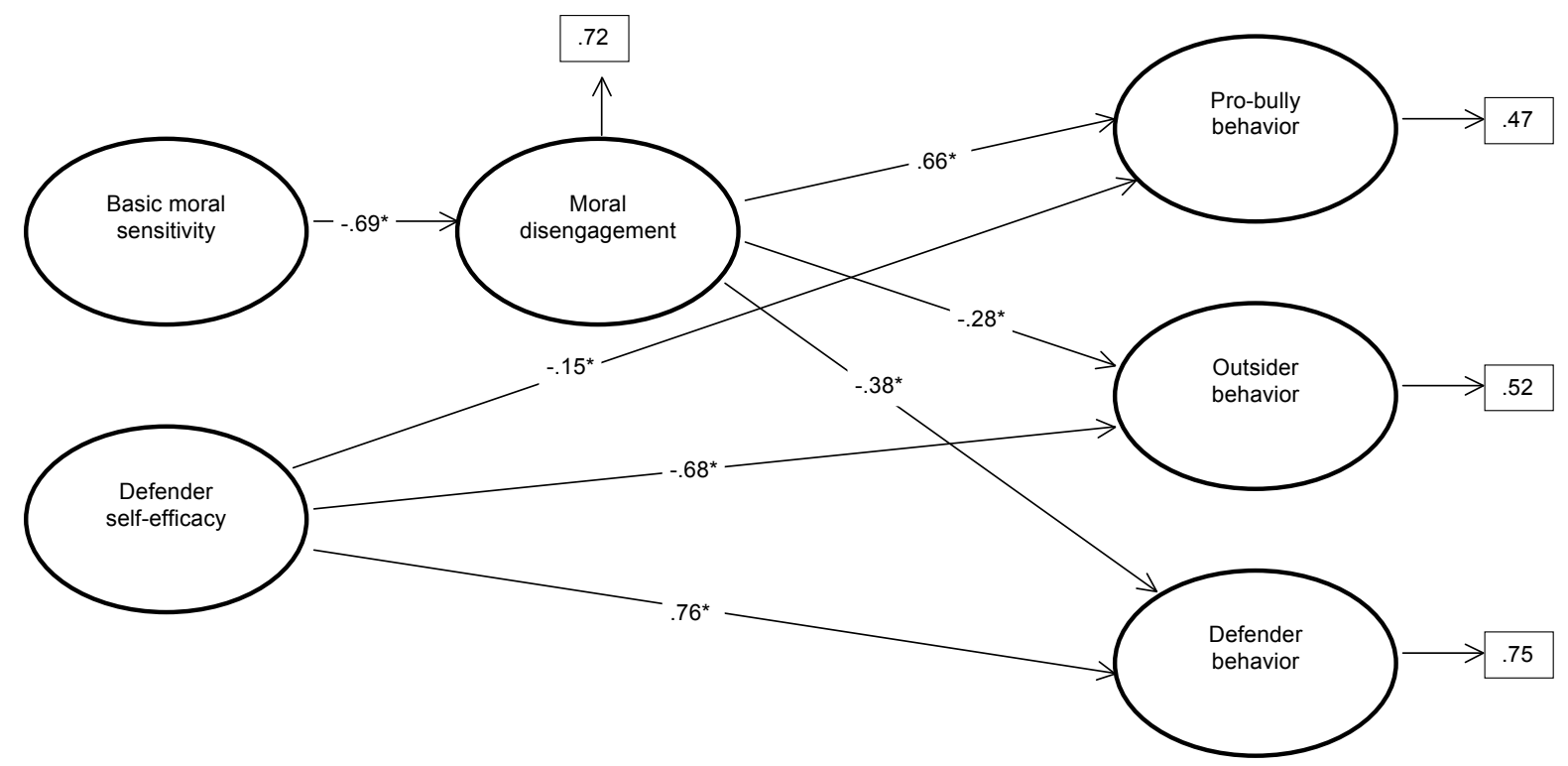

Figure 1. Contribution of moral disengagement, empathy for the victim and defender self-efficacy to different bystander behavior in bullying. Note: $*=p<.05$.

As in the overall model, in both the male model and female model, there was a significant and negative relationship between basic moral sensitivity and moral disengagement. Basic moral sensitivity was indirectly and negatively related to pro-bully behavior, negatively mediated by moral disengagement in bullying, which in turn was directly and positively related to pro-bully behavior. Although significant, these associations were weaker among girls than boys. Furthermore, moral disengagement was negatively related to outsider behavior and defender behavior among boys and not at all related to these bystander behaviors among girls. As in the overall model, there was also a strong negative relationship between defender selfefficacy and outsider behavior and a strong positive relationship between defender self- 
efficacy and defender behavior for both boys and girls. In addition, a negative association between defender self-efficacy and pro-bully behavior were found only in the female sample.

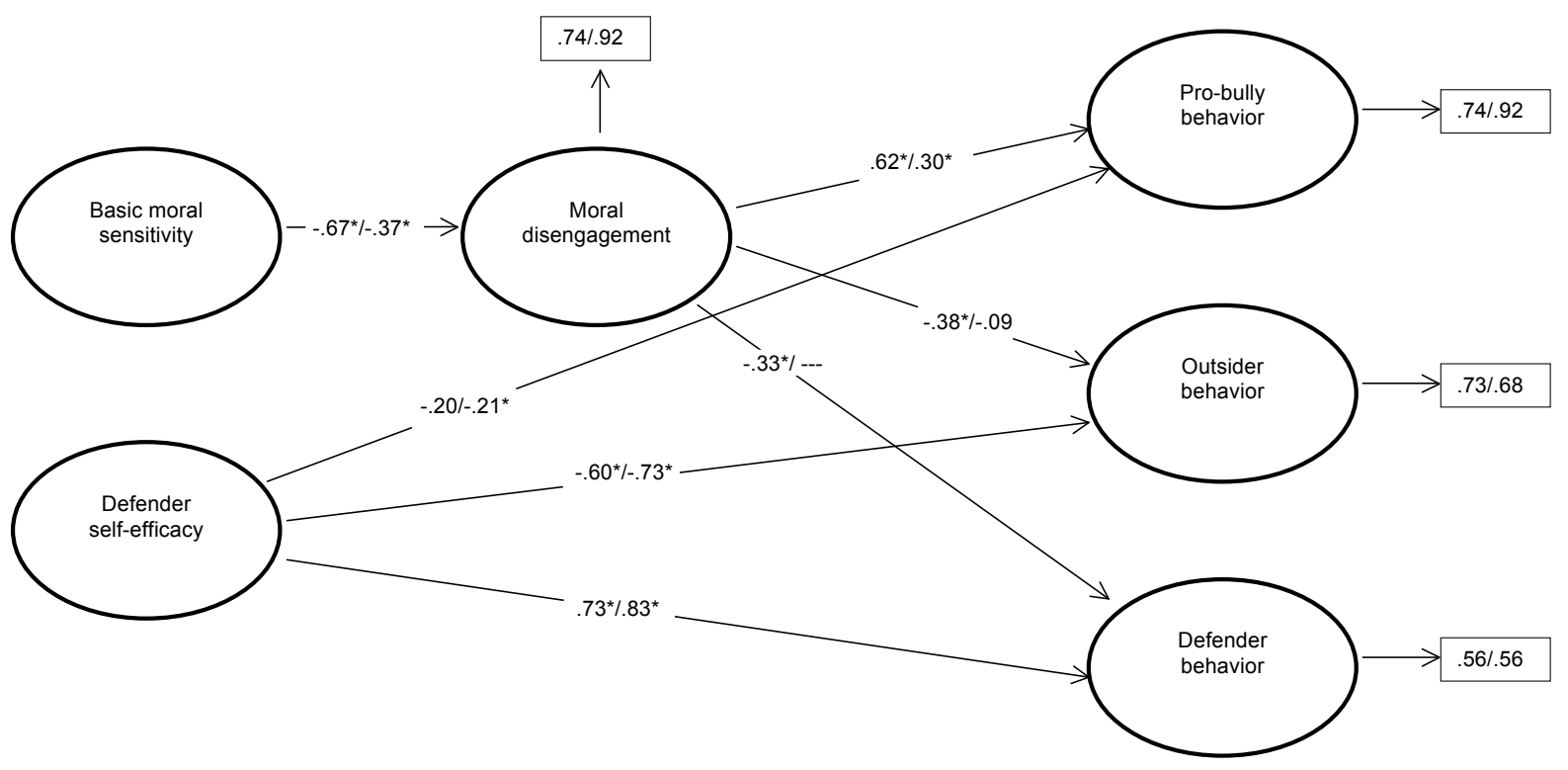

Figure 2. Contribution of moral disengagement, empathy for the victim and defender self-efficacy to different bystander behavior in bullying for boys and girls. Note: $*=p<.05$; gender $=$ boys/girls.

\section{Discussion}

The strong negative association between basic moral sensitivity and moral disengagement in bullying confirms our hypothesis and indicates that children and adolescents who have low basic moral sensitivity are less resistant to moral disengagement than those who have high basic moral sensitivity. In addition, basic moral sensitivity was negatively associated with pro-bully behavior. This pattern might explain why students who bullied others or assisted bullies as shown in the work of Caravita et al. (2009) were more prone to attribute socialconventional characteristics to moral transgressions as compared with their peers. If the basic moral sensitivity is high, it should be harder to cognitively reconstruct the factual moral transgression into a conventional transgression. In other words, the higher basic moral sensitivity adolescents have, the stronger readiness they should have to recognize and make a distinction between moral and conversional transgressions predicted by social-cognitive domain theory and research, at least in simple moral situations (e.g., Nucci, 1981, 2001; Nucci et al., 1996; Tisak et al., 2000; Thornberg, 2010; Turiel, 1983, 2008). In accordance with this, the basic moral sensitivity in bullying was indeed found to be very high in the whole sample (in the possible range of $1-7$, the mean was 5.77 ) but there was a certain individual variation (sd . 1.32), which in turn was linked with moral disengagement and different bystander behavior. In addition, the higher degree of basic moral sensitivity in bullying among girls as compared with boys found in the present study might expand our understanding of why girls are more likely to show positive attitudes toward victims (e.g., Menesini et al., 1997; Pozzoli \& Gini, 2010; Ribgy \& Slee, 1991), less likely to display moral disengagement (Almedia et al., 2010; Bandura et al., 1996, 2001; Barchia \& Bussey, 2010; Obermann, 2011b), and more likely to support or defend victims and less likely to reinforce bullies than boys are (Gini et al., 2008; O’Connell et al., 1999; Salmivalli et al., 1996; Salmivalli \& Voeten, 2004).

The current findings show that moral disengagement for the whole sample was positively associated with pro-bully behavior and negatively associated with outsider and defender behavior, which confirm our hypothesis and support previous findings (Gini, 2006; Menesini 
et al., 2003; Pozzoli et al., 2012). Furthermore, in accordance with prior research, girls were found to demonstrate less moral disengagement as compared with boys (which might, at least in part, be explained by their higher basic moral sensitivity; see above). Moreover, for boys and girls, the higher the levels of moral disengagement, the higher their proneness to assist or reinforce bullies as bystanders in bullying situations. In contrast, whereas lower levels of moral disengagement were associated with both outsider and defender behavior among the boys, moral disengagement was not linked at all to outsider or defender behavior among the girls. The exercise of moral agency has dual aspects according to Bandura (1999). "The inhibitive form is manifested in the power to refrain from behaving inhumanely. The proactive form of morality is expressed in the power to behave humanely" (p. 194). The current findings suggest that variation of moral disengagement in bullying is more relevant to use as a framework to explain the inhibitive form rather than the proactive form of morality, at least in the role of bystander in bullying situations among adolescents.

The findings actually reveal that in order to better explain and predict the full range of bystander behavior in bullying situations, researchers have to consider moral disengagement and defender self-efficacy as well. In line with the self-efficacy framework (Bandura, 1986, 1997), we found that defender self-efficacy was positively associated with defender behavior (cf., Barchia \& Bussey, 2011; Pöyhönen et al., 2012) and negatively associated with outsider behavior for both boys and girls. Hence, whereas high level of defender self-efficacy seem to motivate and engage adolescents to help victims, low level of defender self-efficacy inhibit them from intervening as bystanders, regardless of their level of moral disengagement. These findings are consistent with the socio-cognitive theory of human agency. Bandura (1997) argues that beliefs of personal efficacy constitute the key factor of human agency. "If people believe they have no power to produce results, they will not attempt to make things happen" (p. 3). The current study adds valuable knowledge to the literature of bystander/defender behavior by demonstrating that lower levels of basic moral sensitivity negatively mediated by moral disengagement in bullying explain pro-bully behavior, but defender behavior cannot be sufficiently explained in terms of higher levels of basic moral sensitivity and lower levels of moral disengagement. Even if adolescents see the wrongness of bullying, they may remain as passive bystanders because they do not believe that they are capable of intervening effectively.

Nevertheless, some limitations of this study should be noted. First, our concept of basic moral sensitivity, developed from our readings of social-cognitive domain theory (Nucci, 2001; Turiel, 1983), the four-component model of moral functioning and its concept of moral sensitivity (Jordan, 2007; Narvaez \& Rest, 1995; Rest, 1985), and the social cognition approach to moral development (Arsenio \& Lemerise, 2004; Hoffman, 2000; Narvaez \& Lapsley, 2005), is a new construct measured with only three items. Although the findings indicate the importance of the concept, further empirical and theoretical work is needed to elaborate the concept and the measurement of it, and to test it further. Second, the findings are based on self-reported data. Careless marking, social desirability, and intentionally exaggerated responses among participants might have inflated the estimates. In addition, some associations might be stronger as an effect of shared method variance (Cornell \& Bandyopadhyay, 2010). Third, because of the cross-sectional design, all variables were measured at the same time, and we therefore are not able to pinpoint the direction of effects. Further studies would need to take a longitudinal approach to investigate the directions of the effects. Thus, identified associations as well as drawing causal conclusions based on the associations should be considered with great caution. Finally, a note of caution needs to be sounded regarding the generalization of the findings. This sample of adolescents from a particular area of Sweden may or may not be similar to the population of adolescents with whom the readers primarily work or are interested in. Despite these limitations, the current findings suggest that bullying 
prevention programs can discourage pro-bully behavior among bystanders in bullying situations by enhancing basic moral sensitivity and reducing moral disengagement mechanisms among adolescents, and encouraging defender behavior by enhancing defender self-efficacy among adolescents.

\section{References}

Albiero, P., Matricardi, G., Speltri, D., \& Toso, D. (2009). The assessment of empathy in adolescence: A contribution to the Italian validation of the "Basic Empathy Scale". Journal of Adolescence, 32, 393-408.

Arsenio, W. F., \& Lemerise, E. A. (2004). Aggression and moral development: Integrating social information processing and moral domain models. Child Development, 75, 987-1002.

Bandura, A. (1986). Social foundations of thought and action: A social cognitive theory. Englewood Cliffs, NJ: Prentice-Hall.

Bandura, A. (1997). Self-efficacy: The exercise of control. New York: Freeman and Company.

Bandura, A. (1999). Moral disengagement in the perpetration of inhumanities. Personality and Social Psychology Review, 3, 193-209.

Bandura, A. (2002). Selective moral disengagement in the exercise of moral agency. Journal of Moral Education, 31, 101-119.

Bandura, A., Barbaranelli, C., Caprara, G. V., \& Pastorelli, C. (1996). Mechanisms of moral disengagement in the exercise of moral agency. Journal of Personality and Social Psychology, 71, 364-374.

Bandura, A., Caprara, G. V., Barbaranelli, C., \& Pastorelli, C. (2001). Sociocognitive self-regulatory mechanisms governing transgressive behavior. Journal of Personality and Social Psychology, 80, 125-135.

Barchia, K., \& Bussey, K. (2010). Individual and collective social cognitive influences on peer aggression: Exploring the contribution of aggression efficacy, moral disengagement, and collective efficacy. Aggressive Behavior, 35, 1-14.

Barchia, K., \& Bussey, K. (2011). Predictors of student defenders or peer aggression victims: Empathy and social cognitive factors. International Journal of Behavioral Development, 35, 289-297.

Barriga, A. Q., Sullivan-Cosetti, M., \& Gibbs, J. C. (2009). Moral cognitive correlates of empathy in juvenile delinquents. Criminal Behaviour and Mental Health, 19, 253-264.

Bebeau, M. J., Rest, J. R., \& Narvaez, D. (1999). Beyond the promise: A perspective on research in moral education. Educational Researcher, 28, 18-26.

Bellmore, A., Ma, T-L., You, J., \& Hughes, M. (2012). A two-method investigation of early adolescents' responses upon witnessing peer victimization in school. Journal of Adolescence, 35, 1265-1276.

Bentler, P. M. (1995). EQS 6 Structural Equations Program Manual. Multivariate Software, Inc. Encino, CA.

Cappadocia, M. C., Pepler, D., Cummings, J. G., \& Craig, W. (2012). Individual motivations and characteristics with bystander intervention during bullying episodes among children and youth. Canadian Journal of School Psychology, 27, 201-216.

Caravita, S. C. S., Miragoli, \& Di Blasio, P. (2009). "Why should I behave in this way?" Rule discrimination within the school context related to children's bullying. In L. R. Elling (Ed.), Social development (pp. 269290). New York: Nova Science Publishers.

Cohen, D., \& Strayer, J. (1996). Empathy in conduct-disordered and comparison youth. Developmental Psychology, 32, 988-998.

Cornell, D. G., \& Bandyopadhyay, S. (2010). The assessment of bullying. In S. R. Jimerson, S. M. Swearer \& D. L. Espelage (Eds.), Handbook of bullying in schools: An international perspective (pp. 265-276). New York, NY: Routledge.

Craig, W. M., Pepler, D., \& Atlas, R. (2000). Observations of bullying in the playground and in the classroom. School Psychology International, 21, 22-36

Davidson, P., Turiel, E., \& Black, A. (1983). The effect of stimulus familiarity on the use of criteria and justifications in children's social reasoning. British Journal of Development Psychology, 1, 49-65.

Dovidio, J. F., Piliavin, J. A., Schroeder, D. A., \& Penner, L. A. (2006). The social psychology of prosocial behavior. Mahwah, NJ: Lawrence Erlbaum.

Eslea, M., Menesini, E., Morita, Y., O’Moore, M., Mora-Merchán, J. A., Pereira, B., et al. (2003). Friendship and loneliness among bullies and victims: data from seven countries. Aggressive Behavior, 30, 71-83.

Frisén, A., Hasselblad, T., \& Holmqvist, K. (2012). What actually makes bullying stop? Journal of Adolescence, $35,981-990$.

Gini, G. (2006). Social cognition and moral cognition in bullying: What's wrong? Aggressive Behavior, 32, 528539.

Gini, G., Albiero, P., Benelli, B., \& Alto, G. (2008). Determinants of adolescents' active defending and passive bystanding behavior in bullying. Journal of Adolescence, 31, 93-105. 
Gini, G., Pozzoli, T., \& Hauser, M. (2011). Bullies have enhanced moral competence to judge relative to victims, but lack moral compassion. Personality and Individual Differences, 50, 603-608.

Harel-Fisch, Y., Walsh, S. D., Fogel-Grinvald, H., Amitai, G., Pickett, W., Molcho, M., Due, P., Gaspar de Matos, M., \& Craig, W. (2011). Negative school perceptions and involvement in school bullying: A universal relationship across 40 countries. Journal of Adolescence, 34, 639-652.

Hoffman, M. (2000). Empathy and moral development: Implications for caring and justice. Cambridge: Cambridge University Press.

Hyde, L. W., Shaw, D. S., \& Moilanen, K. L. (2010). Developmental precursors of moral disengagement and the role of moral disengagement in the development of antisocial behavior. Journal of Abnormal Child Psychology, 38, 197-209.

Hymel, S., Rocke-Henderson, N. \& Bonanno, R. A. (2005). Moral disengagement: A framework for understanding bullying among adolescents. Special Issue of Journal of Social Sciences, No. 8, 1-11.

Hymel, S., Schonert-Reichl, K. A., Bonanno, R. A., Vaillancourt, T., \& Rocke Henderson, N. (2010). Bullying and morality: Understanding how good kids can behave badly. In S. R. Jimerson, S. M. Swearer \& D. L. Espelage (Eds.), Handbook of bullying in schools: An international perspective (pp. 101-118). New York, NY: Routledge.

Jimerson, S. R., Swearer, S. M., \& Espelage, D. L. (Eds.) (2010). Handbook of bullying in schools: An international perspective. New York: Routledge.

Jordan, J. (2007). Taking the first step toward a moral action: A review of moral sensitivity measurement across domains. The Journal of Genetic Psychology, 168, 323-359.

Kärnä, A., Voeten, M., Poskiparta, E., \& Salmivalli, C. (2011). Vulnerable children in varying classroom contexts: Bystanders' behaviors moderate the effects of risk factors on victimization. Merrill-Palmer Quarterly, 56, 261-282.

Latané, B. \& Darley, J. M. (1970). The unresponsive bystander: Why doesn't he help? New York: Meredith Corporation.

Narvaez, D., \& Lapsley, D. K. (2005). The psychological foundations of everyday morality and moral expertise. In D. K. \& F. C. Power (Eds.), Character psychology and character education (pp. 140-165). Notre Dame: University of Notre Dame Press.

Narvaez, D., \& Rest, J. (1995). The four components of acting morally. In W. M. Kurtines \& J. L. Gewirtz (Eds.), Moral development: An introduction (pp. 385-399). Boston: Allyn and Bacon.

Narvaez, D., \& Vaydich, J. L. (2008). Moral development and behaviour under the spotlight of the neurobiological sciences. Journal of Moral Education, 37, 289-312.

Nucci, L.P. (1981). Conceptions of personal issues: A domain distinct from moral or societal concepts. Child Development, 52, 114-121.

Nucci, L. P. (2001). Education in the moral domain. Cambridge: Cambridge University Press.

Nucci, L., Camino, C., \& Sapiro, C.M. (1996). Social class effects on northeastern Brazilian children's conceptions of areas of personal choice and social regulation. Child Development, 67, 1223-1242.

Menesini, E., Esla, M., Smith, P. K., Genta, M. L., Giannetti, E., Fonzi, A., et al. (1997). A cross-national comparison of children's attitudes towards bully/victim problems in school. Aggressive Behavior, 29, 1-13.

Menesini, E., Sanchez, V., Fonzi, A., Ortega, R., Costabile, A., \& Feudo, G. L. (2003). Moral emotions and bullying: A cross-national comparison of differences between bullies, victims and outsiders. Aggressive Behavior, 29, 515-530.

Obermann, M-L. (2011a). Moral disengagement among bystanders to school bullying. Journal of School Violence, 10, 239-257.

Obermann, M-L. (2011b). Moral disengagement in self-reported and peer-nominated school bullying. Aggressive Behavior, 37, 133-144.

O’Connell, P., Pepler, D., \& Craig, W. (1999). Peer involvement in bullying: Insights and challenges for intervention. Journal of Adolescence, 22, 437-452.

Oh, I., \& Hazler, R. J. (2009). Contributions of personal and situational factors to bystanders' reactions to school bullying. School Psychology International, 30, 291-310.

Olweus, D. (1993). Bullying at school. Cambridge, MA: Blackwell.

Paciello, M., Fida, R., Tramontano, C., Lupinetti, C., \& Caprara, G. V. (2008). Stability and change in moral disengagement and its impact on aggression and violence in late adolescence. Child Development, 79, $1288-1309$.

Pelton, J., Gound, M., Forehand, R., \& Brody, G. (2004). The moral disengagement scale: Extension with an American minority sample. Journal of Psychopathology and Behavioral Assessment, 26, 31-39.

Perren S., Gutzwiller-Helfenfinger, Malti, T., \& Hymel, S. (2012). Moral reasoning and emotion attributions of adolescent bullies, victims, and bully-victims. British Journal of Developmental Psychology, 30, 511-530.

Pornari, C. D., \& Wood, J. (2010). Peer and cyber aggression in secondary school students: The role of moral disengagement, hostile attribution bias, and outcome expectancies. Aggressive Behavior, 36, 81-94. 
Pozzoli, T., Ang, R. P., \& Ang, R. (2012). Bystanders' reactions to bullying: A cross-cultural analysis of personal correlates among Italian and Singaporean students. Social Development, 21, 687-703.

Pozzoli, T., \& Gini, G. (2010). Active defending and passive bystanding behavior in bullying: The role of personal characteristics and perceived peer pressure. Journal of Abnormal Child Psychology, 38, 815-827.

Pozzoli, T., Gini, G., \& Vieno, A. (2012a). Individual and class moral disengagement in bullying among elementary school children. Aggressive Behavior, 38, 378-388.

Pozzoli, T., Gini, G., \& Vieno, A. (2012b). The role of individual correlates and class norms in defending and passive bystanding behavior in bullying: A multilevel analysis. Child Development, 83, 1917-1931.

Pöyhönen, V., Juvonen, J., \& Salmivalli, C. (2012). Standing up for the victim, siding with the bully or standing by? Bystander responses in bullying situations. Social Development, 21, 722-741.

Rest, J. R. (1985). An interdisciplinary approach to moral education. In M. W. Berkowitz \& F. Oser (Eds.), Moral education: Theory and application (pp. 9-25). New Jersey: Lawrence Erlbaum Associates.

Ribgy, K. \& Slee, P. T. (1991). Bullying among Australian school children: Reported behavior and attitudes toward victims. The Journal of Social Psychology, 131, 615-627.

Salmivalli, C. (1999). Participant role approach to school bullying: Implications for intervention. Journal of Adolescence, 22, 453-459.

Salmivalli, C., Lagerspetz, K., Björkqvist, K., Östermalm, K., \& Kaukiainen, A. (1996). Participant roles and their relations to social status within the group. Aggressive Behavior, 22,1-15.

Salmivalli, C. \& Voeten, M. (2004). Connections between attitudes, group norms, and behaviour in bullying situations. International Journal of Behavioral Development, 28, 246-258.

Salmivalli, C., Voeten, M., \& Poskiparta, E. (2011). Bystander matter: Associations between reinforcing, defending, and the frequency of bullying behavior in classrooms. Journal of Clinical Child \& Adolescent Psychology, 40, 668-676.

Thornberg, R. (2010). A study of children's conceptions of school rules by investigating their judgments of transgressions in the absence of rules. Educational Psychology, 30, 583-603.

Thornberg, R., Tenenbaum, L., Varjas, K., Meyers, J., Jungert, T., \& Vanegas, G. (2012). Bystander motivation in bullying incidents: To intervene or not to intervene? Western Journal of Emergency Medicine, 13, 247252.

Tisak, M.S., Crane-Ross, D., Tisak, J., \& Maynard, A.M. (2000). Mothers' and teachers' home and school rules: Young children's conceptions of authority in context. Merrill-Palmer Quarterly, 46, 168-187.

Turiel, E. (1983). The development of social knowledge. Cambridge: Cambridge University Press.

Turiel, E. (2008). Thought about actions in social domains: Morality, social conventions, and social interactions. Cognitive Development, 23, 136-154.

Warden, D., \& Mckinnon, S. (2003). Prosocial children, bullies, and victims: An investigation of their sociometric status, empathy and social problem-solving strategies. British Journal of Developmental Psychology, $21,367-385$. 